\title{
Analytical Evaluation of Jamming Transition Problem
}

\author{
Ganji, S.S; Barari, Amin; Najafi, M.; Domairry, G.
}

Published in:

Canadian Journal of Physics

DOI (link to publication from Publisher):

10.1139/p11-049

Publication date:

2011

\section{Document Version}

Early version, also known as pre-print

Link to publication from Aalborg University

Citation for published version (APA):

Ganji, S. S., Barari, A., Najafi, M., \& Domairry, G. (2011). Analytical Evaluation of Jamming Transition Problem. Canadian Journal of Physics, 89(6), 729-738. https://doi.org/10.1139/p11-049

\section{General rights}

Copyright and moral rights for the publications made accessible in the public portal are retained by the authors and/or other copyright owners and it is a condition of accessing publications that users recognise and abide by the legal requirements associated with these rights.

- Users may download and print one copy of any publication from the public portal for the purpose of private study or research.

- You may not further distribute the material or use it for any profit-making activity or commercial gain

- You may freely distribute the URL identifying the publication in the public portal -

\section{Take down policy}

If you believe that this document breaches copyright please contact us at vbn@aub.aau.dk providing details, and we will remove access to the work immediately and investigate your claim. 


\title{
Analytical evaluation of jamming transition problem
}

\author{
S.S. Ganji, A. Barari, M. Najafi, and G. Domairry
}

\begin{abstract}
This paper applies two powerful analytical approximation methods to the jamming transition problem (JTP) of traffic flow networks. The governing equations are modeled on the Lorentz system and take the form of a nonlinear nonconservative oscillator. We describe and implement the homotopy perturbation method (HPM) and the variational iteration method (VIM) to compute approximations to the JTP solution. Their solutions are compared with the purely numerical fourth-order Runge-Kutta solution. We conclude that both HPM and VIM provide highly accurate analytical solutions to the nonlinear jamming transition problem.
\end{abstract}

PACS Nos: 89.40.Bb, 02.60.Cb

\begin{abstract}
Résumé : Nous appliquons ici deux méthodes analytiques approximatives au problème de la transition de blocage (jamming) de la circulation dans les réseaux («JTP »). Les équations gouvernantes sont inspirées du système de Lorentz et prennent la forme d'un oscillateur non conservatif non linéaire. Nous décrivons et utilisons la méthode de perturbation homotopique («HPM ») et la méthode itérative variationnelle («VIM ») pour calculer les approximations aux solutions du problème de la transition de blocage. Nous comparons ces solutions à la solution obtenue directement par une méthode numérique de Runge-Kutta du quatrième ordre. Nous concluons que « HPM » et «VIM » fournissent des solutions analytiques très précises au problème non linéaire de la transition de blocage.
\end{abstract}

[Traduit par la Rédaction]

\section{Introduction}

Because small-world [1] and scale-free [2] properties are ubiquitous in many natural and man-made networks [3, 4], the flow properties of the transported entities (such as traffic, information, energy, or chemicals) are of primary interest. A vehicular traffic flow network represents a multibody system of strongly interacting vehicles. In this context, the dynamics of congestion as it relates to highway network structure is a topic of great practical interest [5-7]. For example, earlier studies have analyzed traffic congestion as a phase transition phenomenon in complex networks by defining various congestion factors or order parameters [7].

Traffic congestion occurs when the volume of traffic flow exceeds the largest admissible capacity of a node, especially at bottlenecks such as crossroads, on-ramps, and off-ramps. According to one widely cited study, in 2005 highway congestion resulted in 4.2 billion hours of delay and cost drivers 2.9 billion gallons of additional fuel, for total damages of $\$ 78$ billion to highway users. This enormous negative impact has led highway and urban network planners to draw upon traffic flow studies by experts from a variety of disciplines, including mathematics, engineering, urban planning, and logistics.

Most theoretical models of traffic flow can readily be clas- sified as microscopic, macroscopic, or kinetic [8, 9]. A microscopic model is like a magnifying glass, in that it focuses on a single vehicle that obeys certain rules. Microscopic traffic models therefore study the individual movements of vehicles and interactions between vehicle pairs, particularly in terms of free driving, car following, and lane changing. Usually, an ordinary differential equation (ODE) equation is written down for each mode [10-12]. In contrast, macroscopic traffic models measure the effects of vehicle interactions in terms of collective variables. Similar to fluid dynamics, they employ a system of partial differential equations (PDEs) to balance conservation laws for quantities such as the density of vehicles and the mean velocity. There are two common classes of macroscopic models. First-order models, such as LWR [13, 14], describe traffic as a continuous function of the vehicle density and traffic velocity in space and time. Second-order models include an additional PDE in the average velocity that takes into account the finite "relaxation time" for traffic to adapt to changing conditions [15-17]. In kinetic models, a distribution function $f(t, x, V)$ is defined to express the probability of finding a vehicle at time $t$ in position $x$ moving with velocity $V$. Following methods from statistical mechanics, this function can be computed using an integro-differential equation such as the Boltzmann equation.

Received 17 September 2010. Accepted 15 April 2011. Published at www.nrcresearchpress.com/cjp on .

S.S. Ganji. Department of Transportation Engineering, Islamic Azad University, Science and Research Branch, Tehran, Iran.

A. Barari. Department of Civil Engineering, Aalborg University, Sohngårdsholmsvej 57, 9000 Aalborg, Denmark.

M. Najafi. Department of Civil and Environmental Engineering, University of Texas, Arlington, TX 76019, USA.

G. Domairry. Department of Mechanical Engineering, Babol University of Technology, P.O. Box 484, Babol, Iran.

Corresponding author: A. Barari (e-mail: ab@civil.aau.dk). 
A traffic jam is a microscopic phenomenon and represents one of the most important problems in traffic flow research. Numerous studies have investigated the related problems of traffic jams [1, 5], car accidents [3, 18, 19] and energy dissipation $[20,21]$ within the framework of single-lane traffic models. Recently, some researchers have focused on the jam transition problem (JTP) in its various forms [1-6, 22-24]. They have attacked this problem using thermodynamic [4], hydrodynamic, and kinetic theories $[1,6]$, based on the car-following model [1, 6], Maxell model [23], and cellular automaton model [1, 24]. Two works in this literature have studied the JTP by transforming the traffic model into a nonlinear oscillator with a restoring damping term, via the Lorentz system [8, 25]. The present paper builds upon this line of investigation.

\section{Governing equations}

The original traffic equations based on the Lorentz system $[7,25,26]$ are,

$\dot{\eta}=-\frac{\eta}{t_{\eta}}+v$

$\dot{v}=-\frac{v}{t_{v}}+g_{v} \tau \eta$

$\dot{\tau}=\frac{\tau_{0}-\tau}{t_{\tau}}-g_{\tau} \eta v$

Here $\eta$ is headway deviation, and $\tau$ is the acceleration/braking time on a velocity deviation $v$. The constant factors $t_{\eta}, t_{v}$, and $t_{\tau}$ are the corresponding relaxation times, and $g_{v}$, and $g_{\tau}$ are positive constants. This system of equations does not take into account fluctuations of the characteristic acceleration/braking time. Feedback in this system causes $v$ to increase and is the reason for traffic jam formation. In the general case, (1)-(3) have no analytical solution. Reference 10 , therefore used the simplifying assumptions $t_{\eta} \gg t_{\tau}$ and $t_{\eta} \approx t_{v}$, which taken together imply $\dot{\tau} t_{\tau} \approx 0$. Using these assumptions allows us to transform (3) into,

$\tau=\tau_{0}-g_{\tau} t_{\tau} \eta v$

We now introduce the natural scale factors $t_{\eta}$, $\eta_{m}=\left(g_{v} g_{\tau} t_{\tau} t_{\eta}\right)^{-1 / 2}, v_{m}=t_{\eta}^{-3 / 2}\left(g_{v} g_{\tau} t_{\tau}\right)^{-1 / 2}$, and $\tau_{c}=\left(g_{v} t_{\eta}^{2}\right)^{-1}$ for time, headway deviation, velocity deviation, acceleration/ braking time, respectively. We also define $g_{v} t_{\tau} t_{\eta}^{2}$, a noise term in the characteristic acceleration/braking time $\tau_{0}$. Then, after substituting (4) into (2), system (1)-(3) is transformed into a nonlinear stochastic oscillator [10],

$\ddot{\eta}+\dot{\eta}\left(1+\sigma+\eta^{2}\right)-\eta(\varepsilon-\sigma)-\eta^{3}=0$

where

$\sigma \equiv \frac{t_{\eta}}{t_{v}} \quad$ and $\quad \varepsilon \equiv \frac{\tau_{0}}{\tau_{c}}$

Due to the presence of the third-order nonlinear term, it is very difficult to find an exact solution for the governing equation. In this paper, we apply two analytical methods to the nonlinear nonconservative oscillator.
Table 1. Different values of parameters $\varepsilon, \sigma$, and $t$.

\begin{tabular}{llll}
\hline Mode & $\varepsilon$ & $\sigma$ & $t$ \\
\hline 1 & 0.25 & 0.75 & 0.25 \\
2 & 0.75 & 2.50 & 0.50 \\
3 & 3.25 & 0.75 & 0.75 \\
4 & 2.00 & 0.75 & 1.00 \\
\hline
\end{tabular}

\section{Analytical methods}

Most scientific problems and physical phenomena are nonlinear to some extent. Consequently, scientists have developed many techniques for obtaining analytical solutions that reasonably approximate the exact solutions of nonlinear systems [27]. Both purely numerical and semi-analytical calculation methods have been steadily improving. In recent years several techniques combining the two approaches have drawn special attention, such as the Adomian decomposition method (ADM) [28], the homotopy perturbation method (HPM) [2934], parameterized perturbation [35], the variational iteration method (VIM) [36-38], the Lindstedt-Poincaré method [39], the parameter-expanding method (PEM) [40], the energy balance method (EBM) [41, 42], and the max-min approach (MMA) [43, 44]. As this work draws on both HPM and VIM, a short explanation of these methods follows.

\subsection{Homotopy perturbation method}

The HPM is an effective means of solving nonlinear differential equations. A complex, nonlinear differential equation is transformed into a series of linear and nonlinear differential equations, each one simpler than the original. These equations are solved iteratively. The series of solutions is then summed to complete the answer, provided the convergence criteria are maintained. When using HPM, the stability of the solution needs to be verified through examples. Consequently, HPM is enhanced by prior assumptions that reinforce the stability of the nonlinear dynamic, even if a given linear part of the transformed system is not stable.

To explain the basic idea of the HPM, consider the nonlinear differential equation,

$A(u)-f(r)=0, \quad r \in \Omega$

This equation is subject to the boundary condition,

$B\left(u, \frac{\partial u}{\partial n}\right)=0, \quad r \in \Gamma$

where $A$ is a differential operator, $B$ a boundary operator, $f(r)$ is a known analytical function, $\Gamma$ is a boundary defined in the domain $\Omega$, and $\partial u / \partial n$ denotes differentiation along the outward normal to this boundary. Generally speaking, a differential operator $A$ can be divided into a linear part $L$ and a nonlinear part $N$. Equation (7) therefore can be rewritten as follows,

$L(u)+N(u)-f(r)=0$

A homotopy expression $H(v, p)$ based on (9), using an auxiliary variable $H(r, p)$ with $p \in[0,1]$, can be defined as, 
Table 2. Comparisons between DTM and RK4 for mode 1 .

\begin{tabular}{llllllll}
\hline No. & $A$ & $\mathrm{RKM}$ & $\mathrm{HPM}_{n=1}=\mathrm{VIM}_{n=1}$ & $\mathrm{HPM}_{n=2}$ & $\mathrm{VIM}_{n=2}$ & $\mathrm{HPM}_{n=3}$ & $\mathrm{VIM}_{n=3}$ \\
\hline 1 & 0.1 & 0.09862008 & 0.09840625 & 0.098644 & 0.09864439 & 0.09861789 & 0.09861790 \\
& & & $(0.00217)$ & $(0.000247)$ & $(0.000246)$ & $\left(2.2206 \times 10^{-5}\right)$ & $\left(2.2105 \times 10^{-5}\right)$ \\
2 & 0.2 & 0.19708585 & 0.1966250 & 0.1971393 & 0.1971392 & 0.1970809 & 0.1970810 \\
& & & $(0.002338)$ & $(0.000271)$ & $(0.000271)$ & $\left(2.4862 \times 10^{-5}\right)$ & $\left(2.4355 \times 10^{-5}\right)$ \\
3 & 0.3 & 0.29524580 & 0.2944688 & 0.2953391 & 0.2953386 & 0.2952369 & 0.2952372 \\
& & & $(0.002632)$ & $(0.000316)$ & $(0.000314)$ & $\left(3.0144 \times 10^{-5}\right)$ & $\left(2.9128 \times 10^{-5}\right)$ \\
4 & 0.5 & 0.49007267 & 0.4882812 & 0.4903106 & 0.4903068 & 0.4900471 & 0.4900486 \\
& & & $(0.003656)$ & $(0.000485)$ & $(0.000478)$ & $\left(5.2237 \times 10^{-5}\right)$ & $\left(4.9176 \times 10^{-5}\right)$ \\
5 & 0.7 & 0.68204392 & 0.67834387 & 0.6826085 & 0.6825902 & 0.6819734 & 0.6819806 \\
& & & $(0.005425)$ & $(0.000828)$ & $(0.000801)$ & $\left(1.0337 \times 10^{-4}\right)$ & $\left(9.2809 \times 10^{-5}\right)$ \\
6 & 0.9 & 0.87029712 & 0.8631562 & 0.8715784 & 0.8715104 & 0.8701047 & 0.8701354 \\
& & & $(0.008205)$ & $(0.001472)$ & $(0.001394)$ & $(0.0002211)$ & $(0.0001858)$ \\
7 & \multirow{2}{*}{1.0} & 0.96282424 & 0.9531250 & 0.9647217 & 0.9645994 & 0.9625106 & 0.9625699 \\
& & & $(0.010074)$ & $(0.001971)$ & $(0.001844)$ & $(0.000326)$ & $(0.000264)$ \\
\hline
\end{tabular}

Table 3. Comparisons between analytical solutions and RK4 for mode 2.

\begin{tabular}{|c|c|c|c|c|c|c|c|c|}
\hline No. & $A$ & RKM & $\mathrm{HPM}_{n=1}=\mathrm{VIM}_{n=1}$ & $\operatorname{HPM}_{n=2}$ & $\operatorname{VIM}_{n=2}$ & $\mathrm{HPM}_{n=3}$ & $\mathrm{VIM}_{n=3}$ & $\mathrm{HPM}_{n=4}$ \\
\hline \multirow[t]{2}{*}{1} & 0.1 & 0.08716552 & 0.07800000 & 0.09168583 & 0.09168008 & 0.08544825 & 0.08545447 & 0.08769884 \\
\hline & & & $(0.105151)$ & $(0.051859)$ & $(0.051793)$ & $(0.019701)$ & $(0.0196299)$ & $(0.006118)$ \\
\hline \multirow[t]{2}{*}{2} & 0.2 & 0.17402077 & 0.1552500 & 0.1833959 & 0.1833483 & 0.1704012 & 0.1704530 & 0.1751719 \\
\hline & & & $(0.1078653)$ & $(0.05387345)$ & $(0.0536005)$ & $(0.02079981)$ & $(0.02050215)$ & $(0.00661447)$ \\
\hline \multirow[t]{2}{*}{3} & 0.3 & 0.26026565 & 0.23100 & 0.2751887 & 0.2750195 & 0.2543498 & 0.245367 & 0.2622209 \\
\hline & & & $(0.1124451)$ & $(0.057338)$ & $(0.056688)$ & $(0.022730)$ & $(0.022012)$ & $(0.0075127)$ \\
\hline \multirow[t]{2}{*}{5} & 0.7 & 0.5939870 & 0.50400 & 0.647488 & 0.644340 & 0.5682746 & 0.5720924 & 0.6050372 \\
\hline & & & $(0.1514966)$ & $(0.090071)$ & $(0.0847709)$ & $(0.043288)$ & $(0.0368604)$ & $(0.018603)$ \\
\hline \multirow[t]{2}{*}{6} & 0.9 & 0.7514723 & 0.612000 & 0.8439599 & 0.8353042 & 0.700680 & 0.7118697 & 0.7772944 \\
\hline & & & $(0.1855987)$ & $(0.123075)$ & $(0.1115569)$ & $(0.0675912)$ & $(0.0527000)$ & $(0.0343620)$ \\
\hline \multirow[t]{2}{*}{7} & 1.0 & 0.8274996 & 0.656250 & 0.9480794 & 0.9344574 & 0.7563276 & 0.7745540 & 0.8669796 \\
\hline & & & $(0.2096483)$ & $(0.145716)$ & $(0.1292542)$ & $(0.0860085)$ & $(0.0639826)$ & $(0.0477100)$ \\
\hline
\end{tabular}

Table 4. Comparisons between analytical solutions and RK4 for mode 3.

\begin{tabular}{|c|c|c|c|c|c|c|c|c|}
\hline No. & $A$ & RKM & $\mathrm{HPM}_{n=1}=\mathrm{VIM}_{n}$ & $\mathrm{HPM}_{n=2}$ & $\mathrm{VIM}_{n=2}$ & $\mathrm{HPM}_{n=3}$ & $\mathrm{VIM}_{n=3}$ & $\mathrm{HPM}_{n=4}$ \\
\hline 1 & 0.1 & 0.152310286 & $\begin{array}{l}0.1700312 \\
(0.1163474)\end{array}$ & $\begin{array}{l}0.1473258 \\
(0.032726)\end{array}$ & $\begin{array}{l}0.14772089 \\
(0.03349347)\end{array}$ & $\begin{array}{l}0.1534875 \\
(0.00772896)\end{array}$ & $\begin{array}{l}0.1535502 \\
(0.00814062)\end{array}$ & $\begin{array}{l}0.1520709 \\
(0.0015718)\end{array}$ \\
\hline 2 & 0.2 & 0.30201269 & $\begin{array}{l}0.3383750 \\
(0.1203999)\end{array}$ & $\begin{array}{l}0.2918897 \\
(0.03351846)\end{array}$ & $\begin{array}{l}0.2909786 \\
(0.0365352)\end{array}$ & $\begin{array}{l}0.3042817 \\
(0.00751293)\end{array}$ & $\begin{array}{l}0.3047919 \\
(0.00920226)\end{array}$ & $\begin{array}{l}0.3015779 \\
(0.0014397)\end{array}$ \\
\hline 3 & 0.3 & 0.446731015 & $\begin{array}{l}0.5033438 \\
(0.1267268)\end{array}$ & $\begin{array}{l}0.4310614 \\
(0.03507614)\end{array}$ & $\begin{array}{l}0.4166422 \\
(0.04166422)\end{array}$ & $\begin{array}{l}0.4499292 \\
(0.00715912)\end{array}$ & $\begin{array}{l}0.4516830 \\
(0.01108497)\end{array}$ & $\begin{array}{l}0.4462033 \\
(0.00118125)\end{array}$ \\
\hline 5 & 0.7 & 0.944675865 & $\begin{array}{l}1.095719 \\
(0.1598888)\end{array}$ & $\begin{array}{l}0.8932223 \\
(0.0544669)\end{array}$ & $\begin{array}{l}0.8677786 \\
(0.0814007)\end{array}$ & $\begin{array}{l}0.9512171 \\
(0.0069243\end{array}$ & $\begin{array}{l}0.9727423 \\
(0.0297101)\end{array}$ & $\begin{array}{l}0.9468584 \\
(0.0023103)\end{array}$ \\
\hline 6 & 0.9 & 1.137784670 & $\begin{array}{l}1.327781 \\
(0.1669876)\end{array}$ & $\begin{array}{l}1.055405 \\
(0.07240384)\end{array}$ & $\begin{array}{l}1.0517854 \\
(0.1054074)\end{array}$ & $\begin{array}{l}1.151774 \\
(0.0122949)\end{array}$ & $\begin{array}{l}1.189564 \\
(0.0455086)\end{array}$ & $\begin{array}{l}1.143335 \\
(0.0048779)\end{array}$ \\
\hline 7 & 1.0 & 1.221359766 & $\begin{array}{l}1.421875 \\
(0.1641735)\end{array}$ & $\begin{array}{l}1.121948 \\
(0.08139451)\end{array}$ & $\begin{array}{l}1.081804 \\
(0.1142628)\end{array}$ & $\begin{array}{l}1.243041 \\
(0.01775152)\end{array}$ & $\begin{array}{l}1.286738 \\
(0.05352885)\end{array}$ & $\begin{array}{l}1.227550 \\
(0.00506812)\end{array}$ \\
\hline
\end{tabular}


Table 5. Comparisons between analytical solutions and RK4 for mode 4.

\begin{tabular}{lllllllll}
\hline No. & $A$ & $\mathrm{RKM}$ & $\mathrm{HPM}_{n=1}=\mathrm{VIM}_{n=1}$ & $\mathrm{HPM}_{n=2}$ & $\mathrm{VIM}_{n=2}$ & $\mathrm{HPM}_{n=3}$ & $\mathrm{VIM}_{n=3}$ & $\mathrm{HPM}_{n=4}$ \\
\hline 1 & 0.1 & 0.1406996223 & 0.1398745 & 0.1437402 & 0.1436377 & 0.1317991 & 0.1319300 & 0.1620000 \\
& & & $(0.0058643)$ & $(0.0216106)$ & $(0.0208821)$ & $(0.0632589)$ & $(0.0623285)$ & $(0.1513892)$ \\
2 & 0.2 & 0.2780529024 & 0.2764975 & 0.2847026 & 0.2838980 & 0.2592030 & 0.2601975 & 0.321000 \\
& & & $(0.0055939)$ & $(0.0239152)$ & $(0.0210215)$ & $(0.0677925)$ & $(0.06421584)$ & $(0.1544566)$ \\
3 & 0.3 & 0.4091027251 & 0.4070034 & 0.4204778 & 0.4178620 & 0.3784202 & 0.3814900 & 0.474000 \\
& & & $(0.0051315)$ & $(0.0278050)$ & $(0.021411)$ & $(0.0749995)$ & $(0.0674958)$ & $(0.1586333)$ \\
4 & 0.5 & 0.6440035561 & 0.6414946 & 0.6697058 & 0.6595486 & 0.5833519 & 0.5937500 & 0.750000 \\
& & & $(0.00389594)$ & $(0.03991003)$ & $(0.02413806)$ & $(0.09417913)$ & $(0.0780331)$ & $(0.1645898)$ \\
5 & 0.7 & 0.8367982153 & 0.8330597 & 0.8815274 & 0.8632800 & 0.7464189 & 0.7625100 & 0.966000 \\
& & & $(0.0044676)$ & $(0.05345279)$ & $(0.03164658)$ & $(0.1080061)$ & $(0.08877672)$ & $(0.1544002)$ \\
6 & 0.9 & 0.9892901799 & 0.9786071 & 1.042271 & 1.027822 & 0.8984767 & 0.9095700 & 1.098000 \\
& & & $(0.01079875)$ & $(0.0535544)$ & $(0.0389489)$ & $(0.09179662)$ & $(0.08058323)$ & $(0.1098867)$ \\
7 & 1.0 & 1.0525736785 & 1.038806 & 1.094068 & 1.087392 & 0.9873721 & 0.9921875 & 1.125000 \\
& & & $(0.0130803)$ & $(0.0394215)$ & $(0.03307891)$ & $(0.0619452)$ & $(0.05737031)$ & $(0.06880846)$ \\
\hline
\end{tabular}

Fig. 1. Comparison of the HPM, VIM, and RK4 results for mode 1.

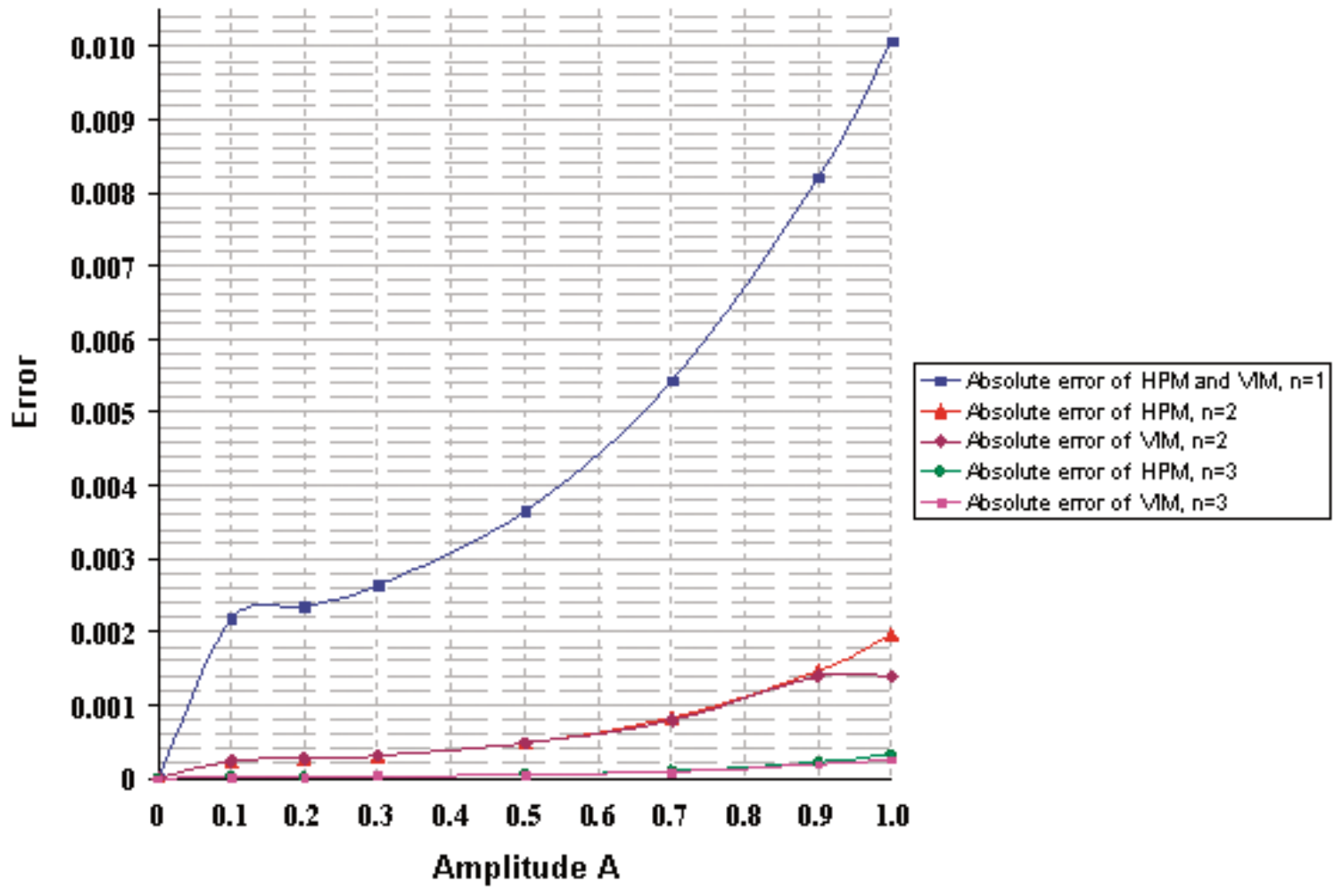

$$
\begin{aligned}
H(v, p) & =(1-p)\left[L(v)-L\left(u_{0}\right)\right]+p[N(v)-f(r)] \\
& =0
\end{aligned}
$$

where $p$ is called the homotopy parameter (inspired by the "small parameter" in perturbation terminology). If $p$ equals 0 , (10) is completely linear, while if $p$ equals 1 , the linear part vanishes, and (10) becomes the same as (7). With a simple manipulation, (10) reduces to the following,

$$
\begin{aligned}
H(v, p) & =L(v)-L\left(u_{0}\right)+p L\left(u_{0}\right)+p[N(v)-f(r)] \\
& =0
\end{aligned}
$$

The initial guess $u_{0}$ (sometimes called $r_{0}$ in the literature) needs to be a good approximation for the solution of (7) However, in the systems field it is a property of the system and can be meaningfully assigned. Similar to erturbation theory, the solution of (10) may be expressed as an approximate linear solution plus a series of increasingly small corrections controlled by powers of the small homotopy parameter,

$v=p^{0} v_{0}+p v_{1}+p^{2} v_{2}+\cdots$

By substituting (12) into (11) and arranging the result in terms of ascending powers of $p$, we achieve an infinite number of differential equations $v$. To solve these, one should 
Fig. 2. Comparison of the HPM, VIM, and RK4 results for mode 2.

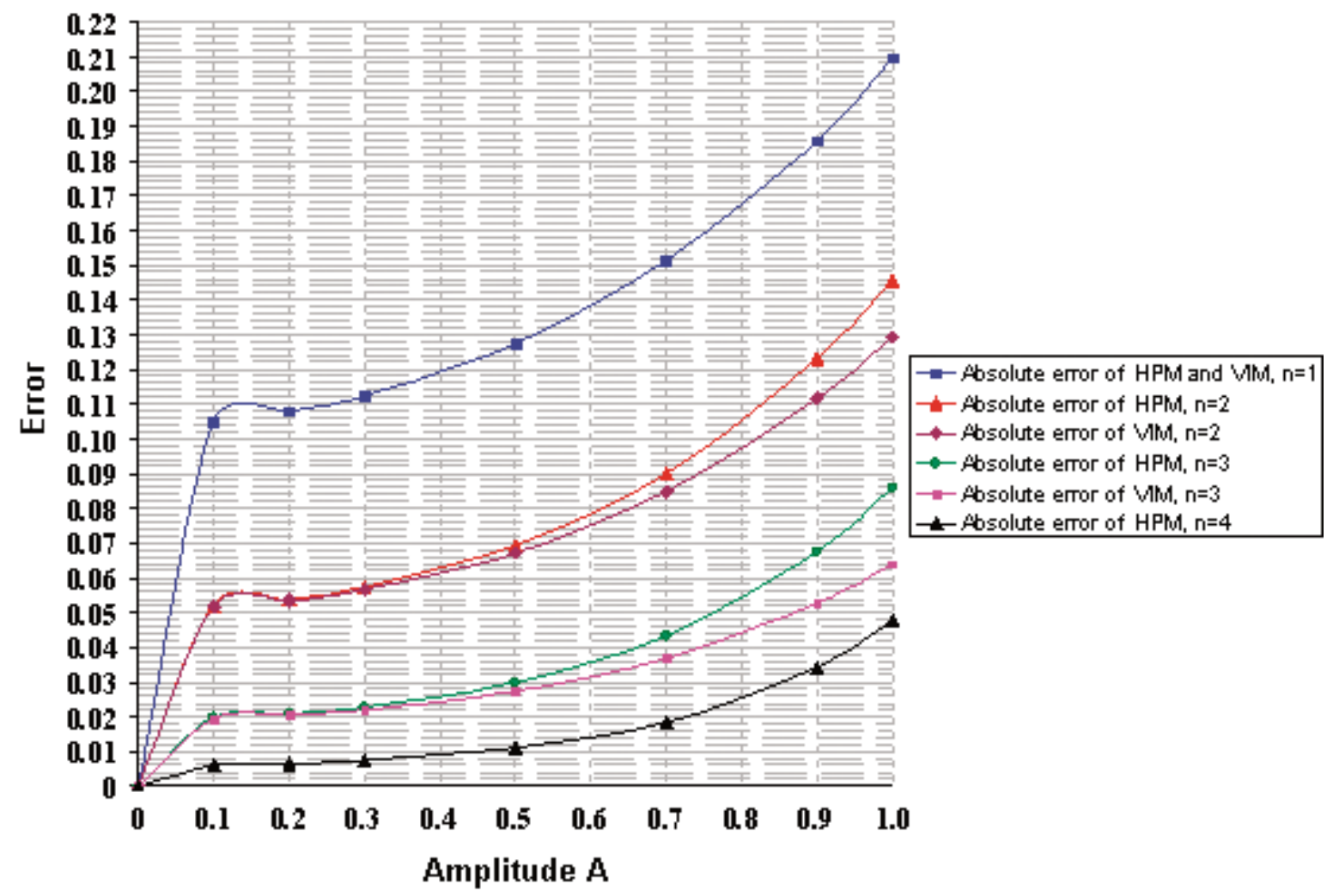

Fig. 3. Comparison of the HPM, VIM, and RK4 results for mode 3.

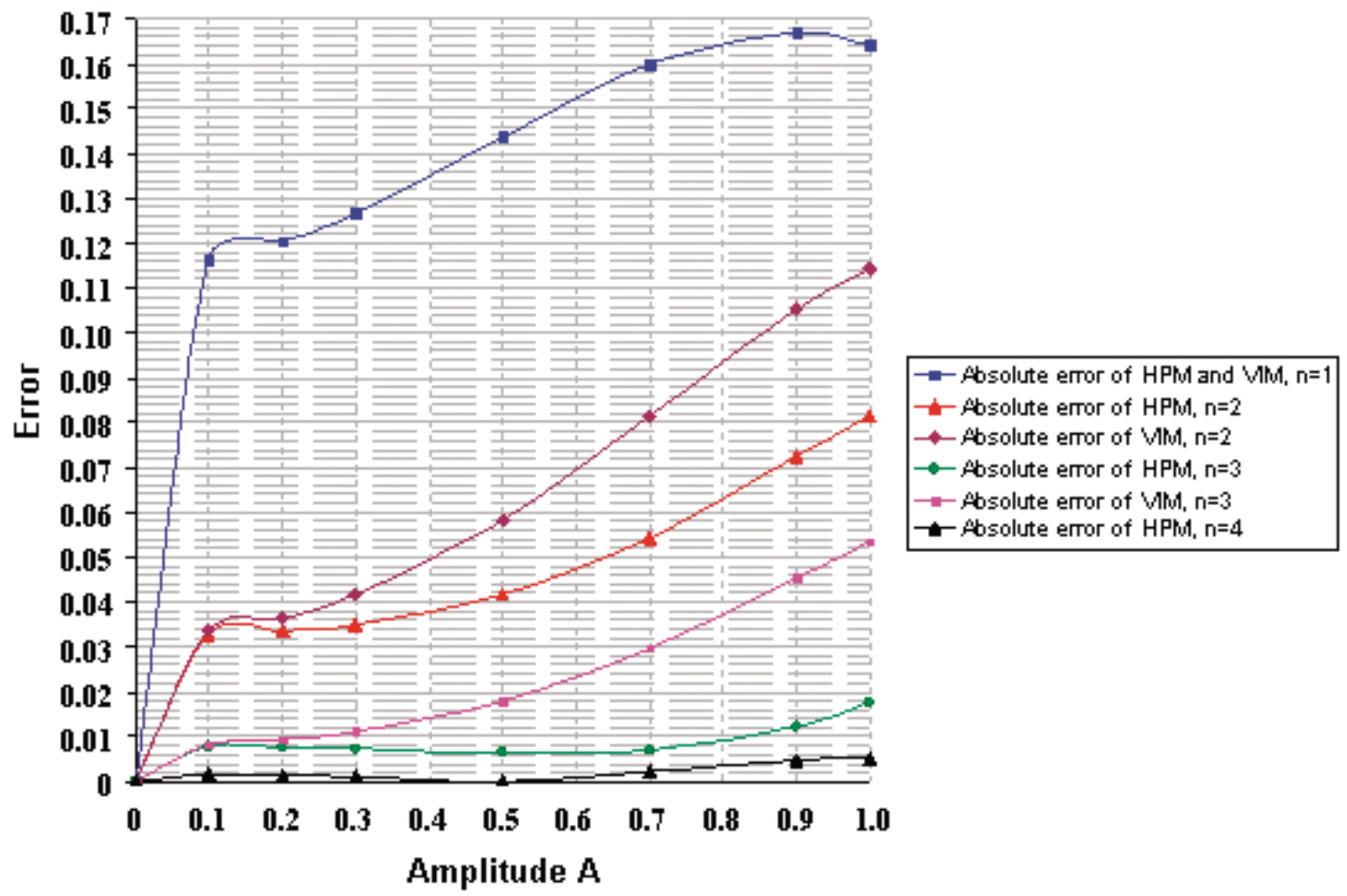


Fig. 4. Comparison of the HPM, VIM, and RK4 results for mode 4.

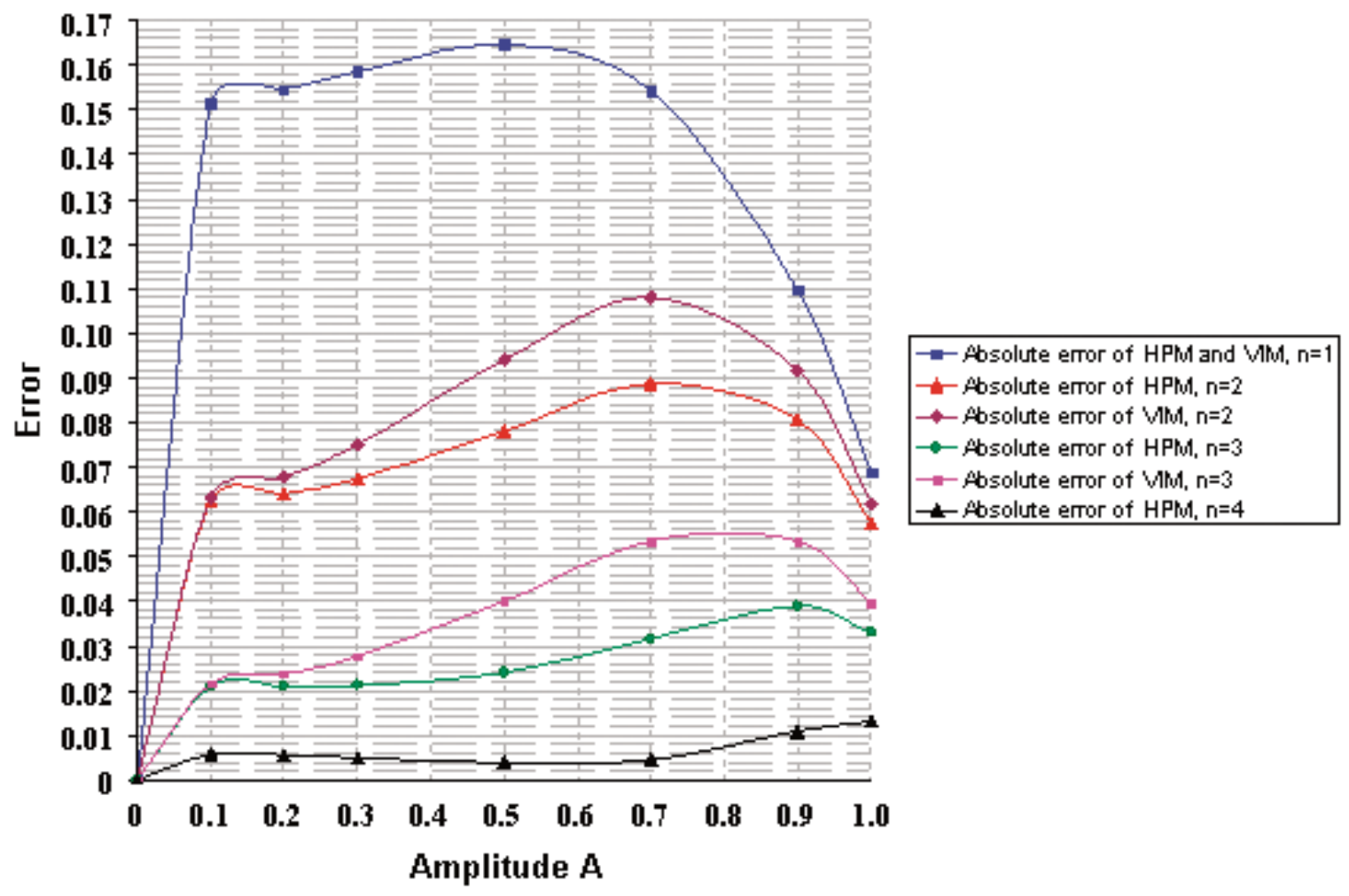

avoid secular terms to produce boundedness. This set of almost simple differential equations with proper initial conditions is then solved. Finally, the approximate solution of (7) can be formed as follows,

$u=\lim _{p \rightarrow 1} v=v_{0}+v_{1}+v_{2}+\cdots$

\subsection{Variational iteration method}

VIM is another powerful method. It uses Lagrange multipliers to identify the optimal values of parameters in a function, and a rapidly convergent sequence is thereby produced. To illustrate the VIM, consider the following differential equation,

$L u+N u=g(t)$

where $L$ is a linear operator, $N$ is a nonlinear operator, and $g(t)$ is an inhomogeneous term. According to the VIM, we can construct the functional as follows,

$u_{n+1}(t)=u_{n}(t)+\int_{0}^{t} \lambda(\tau)\left[L u_{n}(\tau)+N \widetilde{u}_{n}(\tau)-g(\tau)\right] \mathrm{d} \tau$

where $\lambda(\tau)$ is a general Lagrangian multiplier, which can be identified optimally using variational theory.

\section{Applying the Algorithms to JTP}

\subsection{HPM}

In this section, we find a solution for (5) with the initial conditions $\eta(0)=A$ and $\dot{\eta}(0)=0$. According to the HPM, we derive the following functional,

$$
\begin{aligned}
H(v, p)=p\left[\ddot{v}+\ddot{v}\left(1+\sigma+v^{2}\right)\right. & \left.+v(\sigma-\varepsilon)+v^{3}\right] \\
& +(1-p)\left(\ddot{v}-\ddot{v}_{0}\right)=0
\end{aligned}
$$

Assuming $\dot{v}_{0}=0$, after some consolidation and rearrangement of terms in powers of $p$, we have

$$
p^{0}: \quad \ddot{v}_{0}=0
$$

$p^{1}: \quad \ddot{v}_{1}+\dot{v}_{0}\left(1+\sigma+v_{0}^{2}\right)+v_{0}^{3}+v_{0}(\sigma-\varepsilon)=0$

$p^{2}: \quad \ddot{v}_{2}+\dot{v}_{1}\left(1+\sigma+v_{0}^{2}\right)$

$$
+v_{1}\left(\sigma-\varepsilon+3 v_{0}^{2}+2 v_{0} \dot{v}_{0}\right)=0
$$

Solving (17)-(19) yields,

$$
p^{0}: \quad v_{0}=A
$$

$p^{1}: \quad v_{1}=\frac{A\left(\varepsilon-\sigma-A^{2}\right) t^{2}}{2}$

$$
\begin{aligned}
& p^{2}: \quad v_{2}= \\
& \frac{A\left(\sigma-\varepsilon+A^{2}\right)\left[t\left(3 A^{2}+\sigma-\varepsilon\right)+4 A^{2}+4(\sigma+1)\right] t^{2}}{24}
\end{aligned}
$$

Therefore, using (12) and substituting $p=1$, we obtain the approximate solution to the JTP, 
Fig. 5. $q-t$ diagram with $\varepsilon=0.25, \sigma=0.75$, and $A=0.5$.

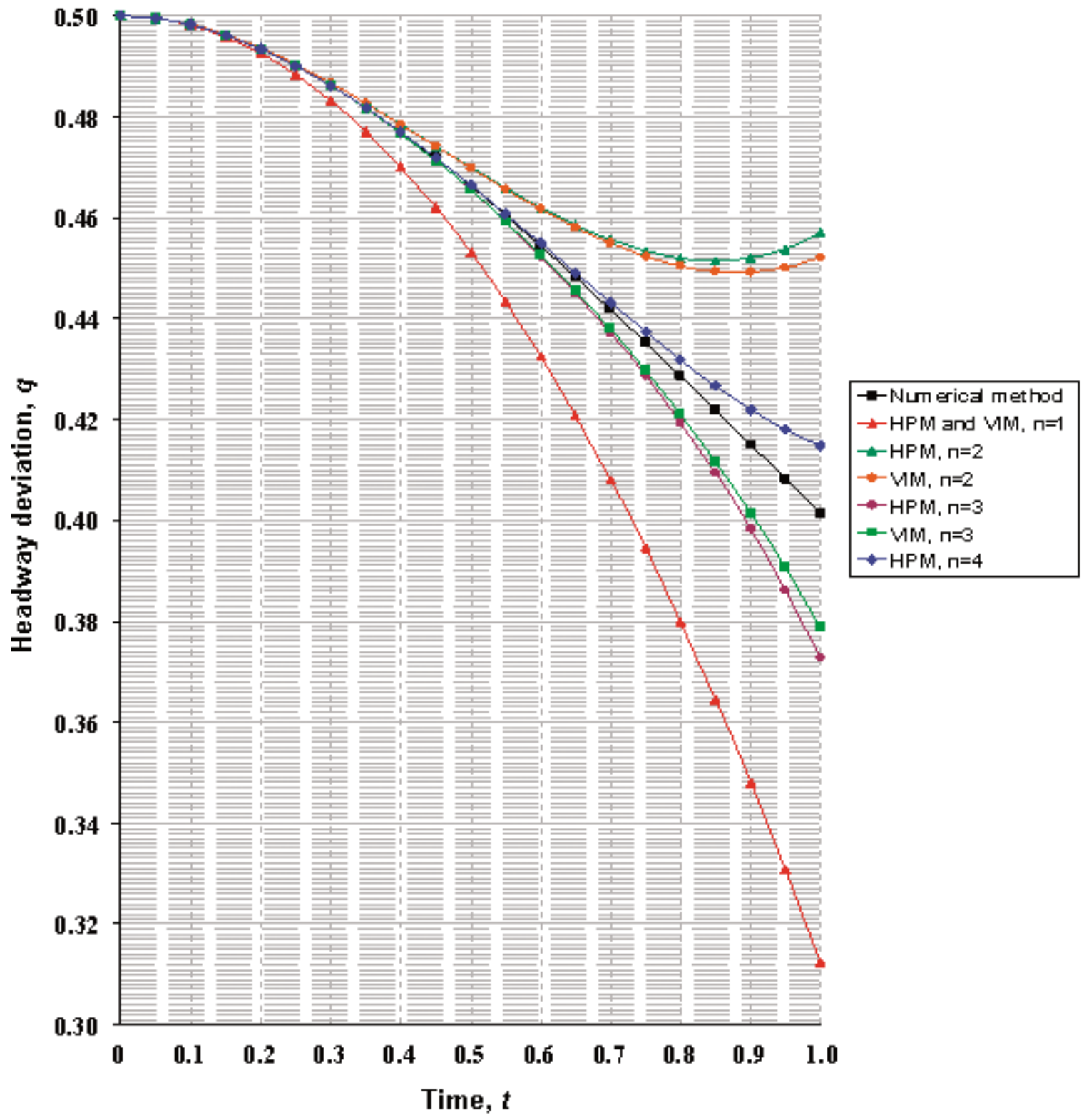

$$
\begin{aligned}
\eta(t)= & A+\frac{A\left(\varepsilon-\sigma-A^{2}\right) t^{2}}{2} \\
& +\frac{A\left(\sigma-\varepsilon+A^{2}\right)\left[t\left(3 A^{2}+\sigma-\varepsilon\right)+4 A^{2}+4(\sigma+1)\right] t^{2}}{24}
\end{aligned}
$$

\subsection{VIM}

To solve (5) using the VIM, we write down the correction function,

$$
\begin{array}{r}
\eta_{n+1}(t)=\eta_{n}(t)+\int_{0}^{t} \lambda(\tau)\left\{\widetilde{\ddot{\eta}} \sim(\tau)+\widetilde{\dot{\eta}} \sim(\tau)\left[1+\sigma+\widetilde{\eta}^{2}(\tau)\right]\right. \\
\left.-\widetilde{\eta \sim}(\tau)(\varepsilon-\sigma)-\widetilde{\eta}^{3}(\tau)\right\} \mathrm{d} \tau
\end{array}
$$

where $\lambda(\tau)$ is a restricted variation. The Lagrange multiplier can therefore be simply identified as $\lambda(\tau)=(\tau-t)$. We obtain the following iteration formula,

$$
\begin{array}{r}
\eta_{n+1}(t)=\eta_{n}(t)+\int_{0}^{t}(\tau-t)\left\{\widetilde{\ddot{\eta}} \sim(\tau)+\widetilde{\dot{\eta}} \sim(\tau)\left[1+\sigma+\widetilde{\eta}^{2}(\tau)\right]\right. \\
\left.-\widetilde{\eta} \sim(\tau)(\varepsilon-\sigma)-\widetilde{\eta}^{3}(\tau)\right\} \mathrm{d} \tau
\end{array}
$$

We start with the initial conditions $\eta(0)=A$ and $\dot{\eta}(0)=0$. Solving the iteration formula (25) using MAPLE, we obtain,

$\eta_{0}(t)=A$

\section{Results and discussion}

In this section, we compare the results of these two analytical, approximate solutions to a solution derived by purely

\section{PROOF/ÉPREUVE}


Fig. 6. $q-t$ diagram with $\varepsilon=3.25, \sigma=0.75$, and $A=1.0$.

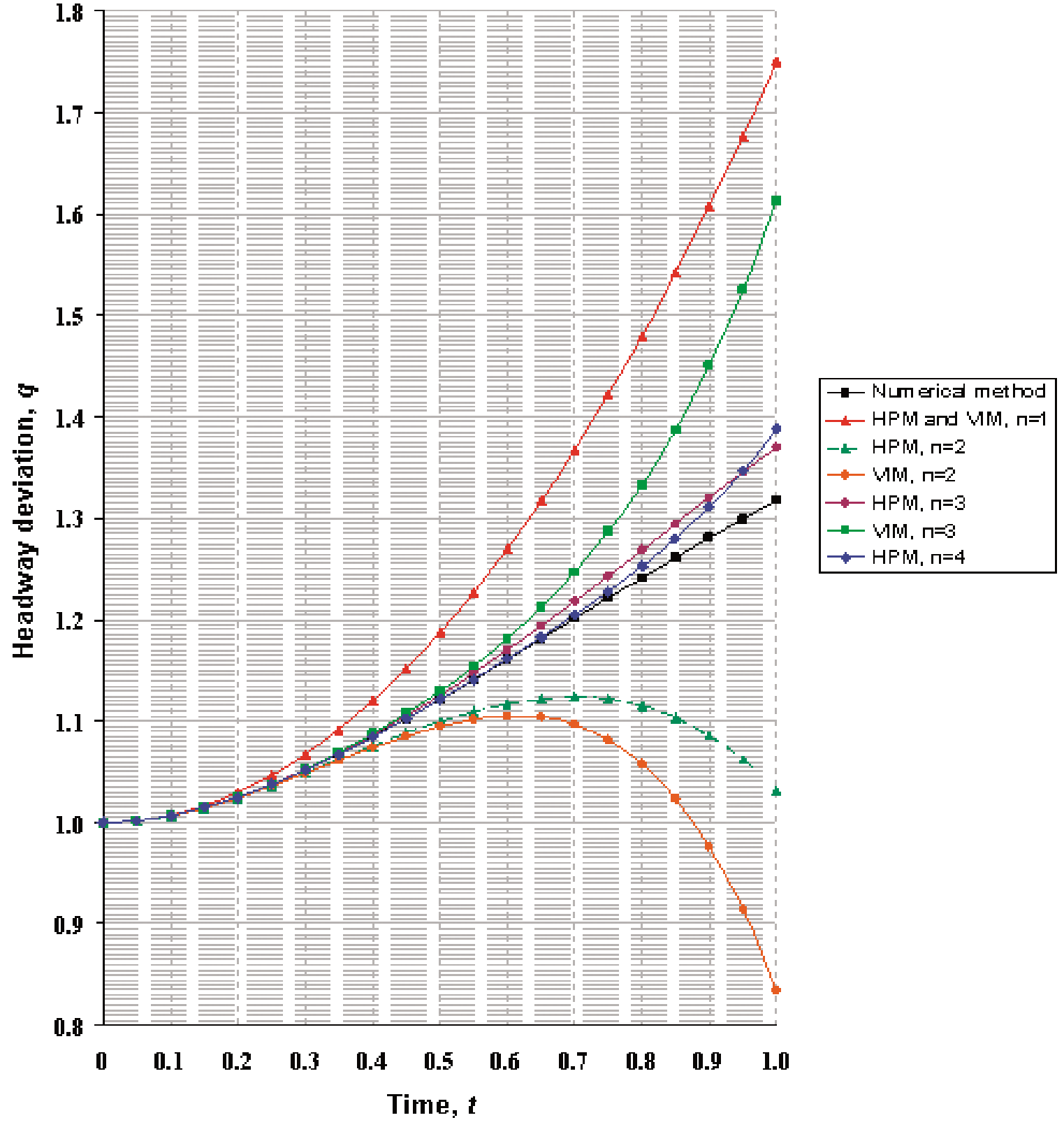

numerical means. Our numerical approach is to transform the second-order differential equations into first-order equations, then solve the system using the Runge-Kutta method (RKM).

Tables 1 through 5 compare the three solutions for different values of the parameters $\varepsilon, \sigma$, and $t$. These four models are defined in Table 1. The analytical and numerical solutions are also plotted in Figs. 1 through 7. In Figs. 1 through 4, the increasing error term is plotted against amplitude; in Figs. 5 through 7, it is plotted against time. The effect of iterations in these tables is obvious and sensible. As expected, the VIM and HPM results are identical in the first step. The interval $A=[0,1]$ is chosen because as presented in Figs. 14 , the slope of the error with respect to amplitude is very steep. The behavior shown in these figures indicates that both presented methods are sensitive to increases in the amplitude of vibration.
The maximum errors related to models 1 to 4 are 1.0074 , $20.96,16.7$, and 16.46, respectively. In the second iteration, as is manifest, the error decreased by $50 \%$ up to $1 / 5$ in the first stage. Although in the first iteration the VIM solution is better than the HPM solution, in the second and later iterations their results are very close to each other. It is worth noting that three or four iterations suffice for VIM and HPM, respectively.

\section{Conclusion}

In this paper, the homotopy perturbation method (HPM) and Variational Iteration Method (VIM) have been applied to a nonlinear oscillator with damping interpreting the jamming transition problem (JTP) in traffic flow. The results obtained show that: 
Fig. 7. $q-t$ diagram with $\varepsilon=2.00, \sigma=0.75$, and $A=1.0$.

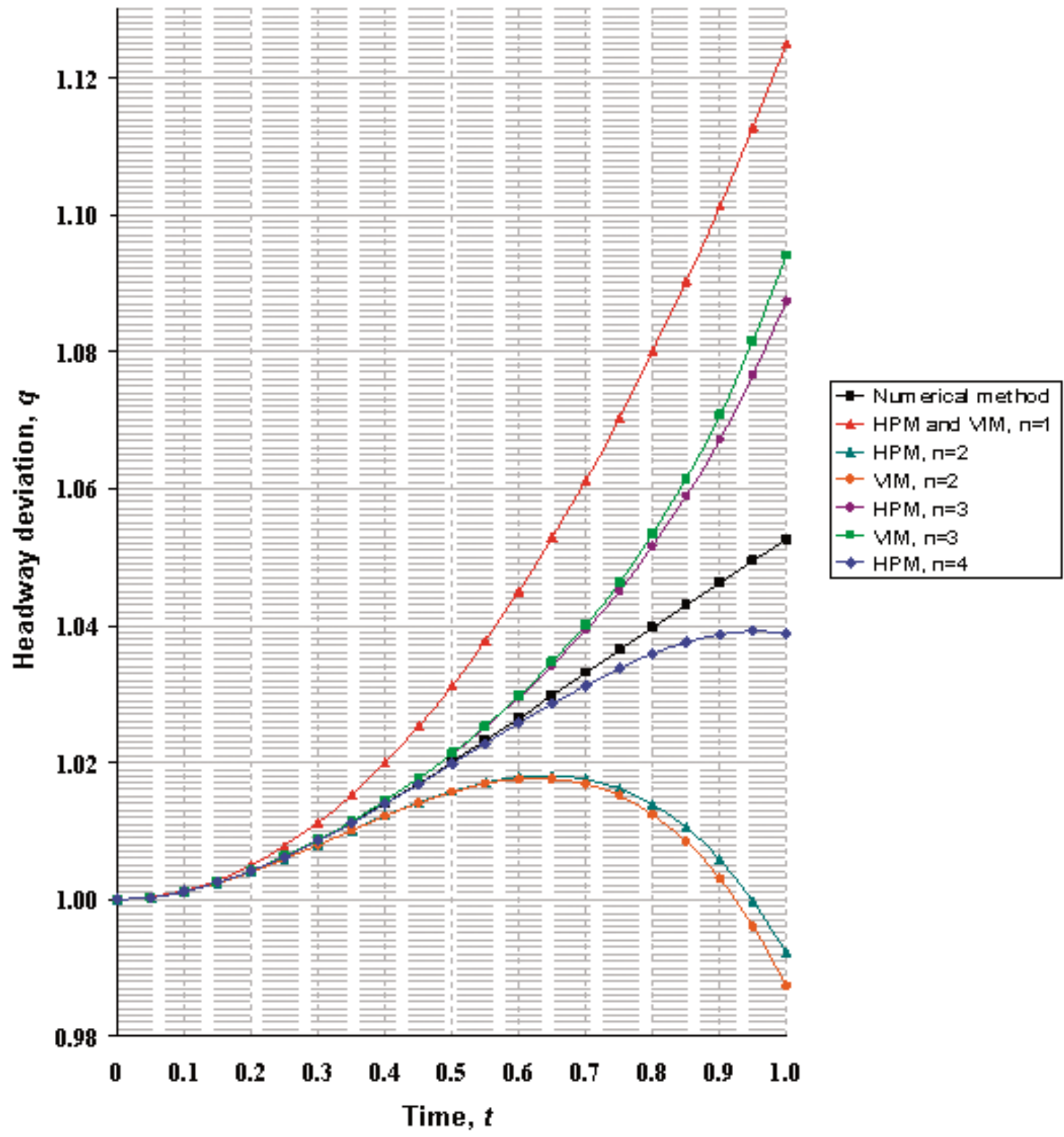

1. HPM and VIM use different functionals, but result in similar analytical approximations to the nonlinear differential equations.

2. The approximations obtained by HPM and VIM converge to the exact solution after a small number of iterations (three or four, respectively, in this application).

3. Compared with a purely numerical solution, the error in the VIM and HPM solution grows more slowly with time than with amplitude.

4. VIM and HPM do not require small parameters in the equations, so the limitation of traditional perturbation methods is eliminated.

5. The calculations in VIM and HPM are simple and straightforward.

\section{References}

1. K. Nagel. Int. J. Mod. Phys. C, 5, 567 (1994). doi:10.1142/ S012918319400074X.
2. L. Gray and D. Griffeath. J. Stat. Phys. 105, 413 (2001). doi:10.1023/A:1012202706850.

3. T. Nagatani. Rep. Prog. Phys. 65, 1331 (2002). doi:10.1088/ 0034-4885/65/9/203.

4. T. Nagatani. Phys. Rev. E, 58, 4271 (1998). doi:10.1103/ PhysRevE.58.4271.

5. D. Chowdhury, L. Santen, and A. Schadscheider. Phys. Rep. 329, 199 (2000). doi:10.1016/S0370-1573(99)00117-9.

6. T. Nagatani. Phys. Rev. E, 61, 3534 (2000). doi:10.1103/ PhysRevE.61.3534.

7. A.V. Khomenko, D.O. Kharchenko, and O.V. Yushchenko. Jamming transition with fluctuations of characteristics acceleration/braking time within Lorentz model, Bulletin of Lviv University, 37, 44, (2004). Available from arXiv:cond-mat/ 0204132v1 [cond-mat.stat-mech].

8. M. Treiber, A. Hennecke, and D. Helbing. Phys. Rev. E, 59, 239 (1999). doi:10.1103/PhysRevE.59.239.

9. D. Helbing. Phys. Rev. E, 53, 2366 (1996). doi:10.1103/ PhysRevE.53.2366. 
10. E.R. Boer. Transp. Res. Part F, 2F, 201 (2000).

11. C.M.J. Tampère. Modelling of traffic flow in congestion for the analysis of automated driver assistance systems: literature review. Report TNO Inro-V+V/2001-59. 2001.

12. D. Helbing. Rev. Mod. Phys. 73, 1067 (2001). doi:10.1103/ RevModPhys.73.1067.

13. M.J. Lighthill and G.B. Whitham. Proc. R. Soc. Lond. A, 299, 281 (1955).

14. P.I. Richards. Oper. Res. 4, 42 (1956). doi:10.1287/opre.4.1. 42.

15. M. Cremer. Der Verkehrsfluss auf Schnellstraßen. Springer, Berlin, Germany. 1979.

16. H.J. Payne. In Models of freeway traffic and control, mathematical models of public systems. Edited by G.A. Bekey. Simulation Council, La Jolla, Calif., USA. 1971.

17. H.J. Payne. Transp. Res. Rec. 722, 68 (1979).

18. D.W. Huang and Y.P. Wu. Phys. Rev. E, 63, 022301 (2001). doi:10.1103/PhysRevE.63.022301.

19. L. Bunketorp, L. Nordholm, and J. Carlsson. Eur. Spine J. 11, 227 (2002). doi:10.1007/s00586-002-0393-y. PMID: 12107791.

20. X.Q. Yang, W. Zhang, K. Qiu, W.T. Xu, G. Tang, and L. Ren. Physica A, 384, 589 (2007). doi:10.1016/j.physa.2007.05.058.

21. D. Shi, S. Zhu, and L. Liu. Physica A, 381, 515 (2007). doi:10. 1016/j.physa.2007.03.054.

22. W. Zhang, W. Zhang, and X.Q. Yang. Physica A, 387, 4657 (2008). doi:10.1016/j.physa.2008.04.004.

23. E. Ben-Naim and P.L. Krapivsky. Phys. Rev. E, 59, 88 (1999). doi:10.1103/PhysRevE.59.88.

24. L. Neubert, H.Y. Lee, and M. Schreckenberg. J. Phys. A, 32, 6517 (1999). doi:10.1088/0305-4470/32/37/303.

25. S.S. Ganji, A. Barari, L.B. Ibsen, and G. Domairry. Cent. Eur. J. Oper. Res. (2011). doi:10.1007/s10100-010-0154-7.

26. A.I. Olemskoi and A.V. Khomenko. Phys. Rev. E, 63, 036116 (2001). doi:10.1103/PhysRevE.63.036116.

27. A.H. Nayfeh. Introduction to perturbation techniques. John Wiley and Sons, New York. 1981.
28. H. Mirgolbabaei, A. Barari, L.B. Ibsen, and M.G. Sfahani. Arch. Civil Mech. Eng. 10, 41 (2010).

29. J.H. He. Phys. Lett. A, 350, 87 (2006). doi:10.1016/j.physleta. 2005.10.005.

30. S.S. Ganji, D.D. Ganji, S. Karimpour, and H. Babazadeh. Int. J. Non-Linear Sci. Numer. Simul. 10, 303 (2009).

31. M.G. Sfahani, S.S. Ganji, A. Barari, H. Mirgolbabaei, and G. Domairry. Earthquake Eng. Eng. Vibr. 9, 367 (2010). doi:10. 1007/s11803-010-0021-5.

32. J.H. He. Int. J. Non-linear Mech. 35, 37 (2000). doi:10.1016/ S0020-7462(98)00085-7.

33. S.S. Ganji, A. Barari, G. Domairry, and P. Teimourzadeh Baboli. Science, 23, 211 (2011).

34. S.R. Seyed Alizadeh, G.G. Domairry, and S. Karimpour. Acta Appl. Math. 104, 355 (2008). doi:10.1007/s10440-008-9261-z.

35. A. Barari, H.D. Kaliji, M. Ghadimi, and G. Domairry. Lat. Am. J. Sol. Struct. Manuscript in preparation (2011).

36. J.H. He. Int. J. Non-linear Mech. 34, 699 (1999). doi:10.1016/ S0020-7462(98)00048-1.

37. J.H. He, G.C. Wu, and F. Austin. Nonlinear Sci. Lett. A, 1, 1 (2010).

38. F. Fouladi, E. Hosseinzadeh, A. Barari, and G. Domairry. J. Heat Transfer Res. 41, 155 (2010). doi:10.1615/HeatTransRes. v41.i2.40

39. J.H. He. Int. J. Non-linear Mech. 37, 315 (2002). doi:10.1016/ S0020-7462(00)00117-7.

40. S.S. Ganji, M.G. Sfahani, S.M. Modares Tonekaboni, A.K. Moosavi, and D.D. Ganji. Math. Probl. Eng. 23, 5915 (2009).

41. M.G. Sfahani, M. Omodvar, A. Barari, S.S. Ganji, and G. Domairry. J. Multi-body Dyn. 225, 66 (2011).

42. S.S. Ganji, D.D. Ganji, Z.Z. Ganji, and S. Karimpour. Acta Appl. Math. 106, 79 (2009). doi:10.1007/s10440-008-9283-6.

43. S.S. Ganji, A. Barari, and D.D. Ganji. Comput. Math. Appl. 61, 1088 (2011). doi:10.1016/j.camwa.2010.12.059.

44. S.S. Ganji, D.D. Ganji, A.G. Davodi, and S. Karimpour. Appl. Math. Model. 34, 2676 (2010). doi:10.1016/j.apm.2009.12. 002 . 